\title{
The Role of Mass and Length in the Sonochemistry of Polymers
}

Mark Schaefer,${ }^{\perp,}$ Burcak Icli, ${ }^{\ddagger}$, Christoph Weder, ${ }^{\ddagger}$ Marco Lattuada, ${ }^{\ddagger}$ Andreas F. M. Kilbinger ${ }^{*}, \perp$ and Yoan C. Simon ${ }^{*},+,+$

$\perp$ Department of Chemistry, University of Fribourg, Chemin du Musée 9, CH-170o Fribourg, Switzerland.

‡ Adolphe Merkle Institute University of Fribourg, Chemin des Verdiers 4, CH-17oo Fribourg, Switzerland.

${ }^{\dagger}$ School of Polymers and High Performance Materials, the University of Southern Mississippi, 118 College Drive, \#5050, Hattiesburg, MS 39406.

Table of content

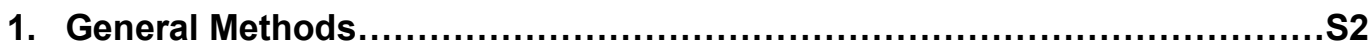

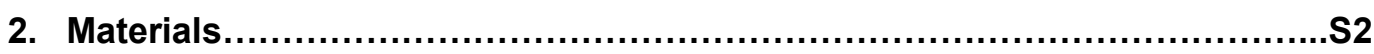

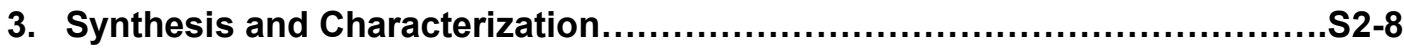

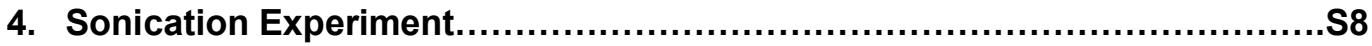

5. Degradation Rate Calculations..................................................... 9

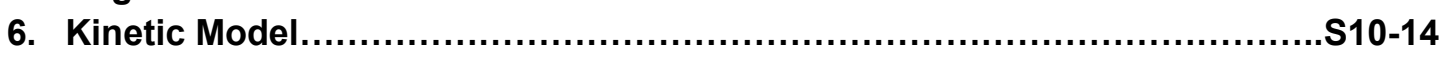

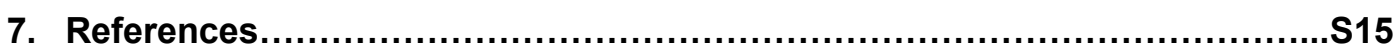


General Methods: Standard nuclear magnetic resonance spectra were recorded at $300 \mathrm{MHz}\left({ }^{1} \mathrm{H}\right.$ $\mathrm{NMR}) / 75 \mathrm{MHz}\left({ }^{13} \mathrm{C}-\mathrm{NMR}\right)$ on a Bruker Avance III 300 spectrometer. All NMR signals are expressed as chemical shifts relative to the signal of tetramethylsilane, using residual solvent signals as reference. Electron spray ionization (ESI) mass spectra were recorded on a Bruker Esquire HCT. Size exclusion chromatography (SEC) experiments were performed on a series $1200 \mathrm{HPLC}$ system equipped with a Polymer Laboratories $5 \mu \mathrm{m}$ mixed-C guard column, two GPC Polymer Laboratories PSS SDV linear M columns (dimension $8 \times 300 \mathrm{~mm}$, particle size $5 \mathrm{~mm}$ ). Data were collected in THF at $30^{\circ} \mathrm{C}$ at a flow rate of $1.0 \mathrm{ml} / \mathrm{min}$ using refractive index $\left(\lambda=658 \mathrm{~nm}, 30^{\circ} \mathrm{C}\right)$ detection recorded using an Optilab REX interferometric refractometer (Wyatt Technology Corp.), a UV detector and miniDawn TREOS light scattering detector. Data analyses were done on an Astra software (Wyatt Technology Corp.). Sonication experiments were performed using Branson Model 450 ultrasonic 1/2 in horn sonicator equipped with $13 \mathrm{~mm}$ sonicator tip. A MX07R-20 Refrigerating/Heating bath from VWR was used to maintain solutions below $10^{\circ} \mathrm{C}$ during sonication experiments.

Materials: Benzylidene-bis(tricyclohexylphosphine)dichlororuthenium (Grubbs' first-generation catalyst), bromine, carbon tetrachloride, chlorotriisopropylsilane, ethylmagnesium chloride solution (2M in THF), ethyl vinyl ether, iodine, oxalyl chloride, 4-pentyn-1-ol, tetrabutylammonium fluoride solution (TBAF, $1 \mathrm{M}$ in THF), and p-toluenesulfonyl chloride were purchased from Sigma-Aldrich and used without further purification. Polystyrene standards were purchased from Alfa Aesar and used without further purification. Triethylene glycol monomethyl ether (Sigma-Aldrich) and potassium carbonate (Acros) were dried under vacuo at $40^{\circ} \mathrm{C}$. Deuterated solvents were purchased from Cambridge Isotope Laboratories and stored over molecular sieves. Spectroscopic grade THF was purchased from Romil. Pyridine (Acros) was freshly distilled from calcium hydride before use. endo-Carbic anhydride (Acros) was heated to $180^{\circ} \mathrm{C}$ for $2 \mathrm{~h}$ and recrystallized from benzene to obtain pure exo-carbic anhydride. exoCarbic imide was synthesized according to the literature ${ }^{1}$.

\section{Synthesis and Characterization:}

\section{Brominated polystyrene (PSBr):}<smiles>CC(C)(C)CC(c1ccccc1)C(C)(C)C</smiles>
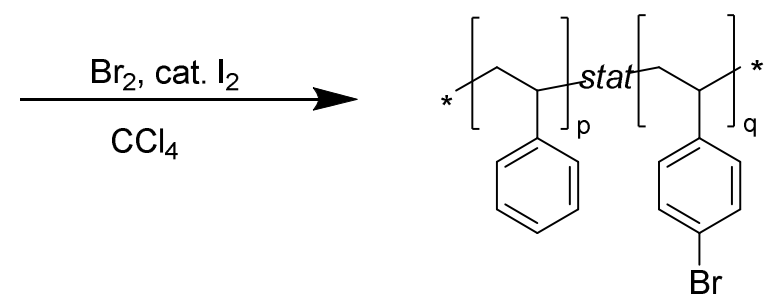

Synthesized with an adapted procedure from literature. ${ }^{2}$

Polystyrene $(250 \mathrm{mg})$ was dissolved in carbon tetrachloride $(10 \mathrm{~mL})$, the solution was cooled to $0^{\circ} \mathrm{C}$ and protected from light. After the addition of a catalytic amount of iodine $(10 \mathrm{mg})$, bromine $(1 \mathrm{~mL})$ was added dropwise via a syringe and the mixture was stirred at room temperature overnight. The solvent and excess bromine were removed under vacuo, the crude product was dissolved in dichloromethane and precipitated into a 10 -fold excess of ice-cold methanol. Filtration resulted in pure product as a slightly yellow powder. For all reactions, quantitative yields were obtained.

${ }^{1} \mathrm{H}$ NMR (300 MHz, $\mathrm{CD}_{2} \mathrm{Cl}_{2}$ ), [ppm]: 7.40-7.00 (m, 2H); 6.70-6.20 (m, 2H); 1.65 (br. s, $\left.1 \mathrm{H}\right) ; 1.37$ (br. s, $2 \mathrm{H})$. 


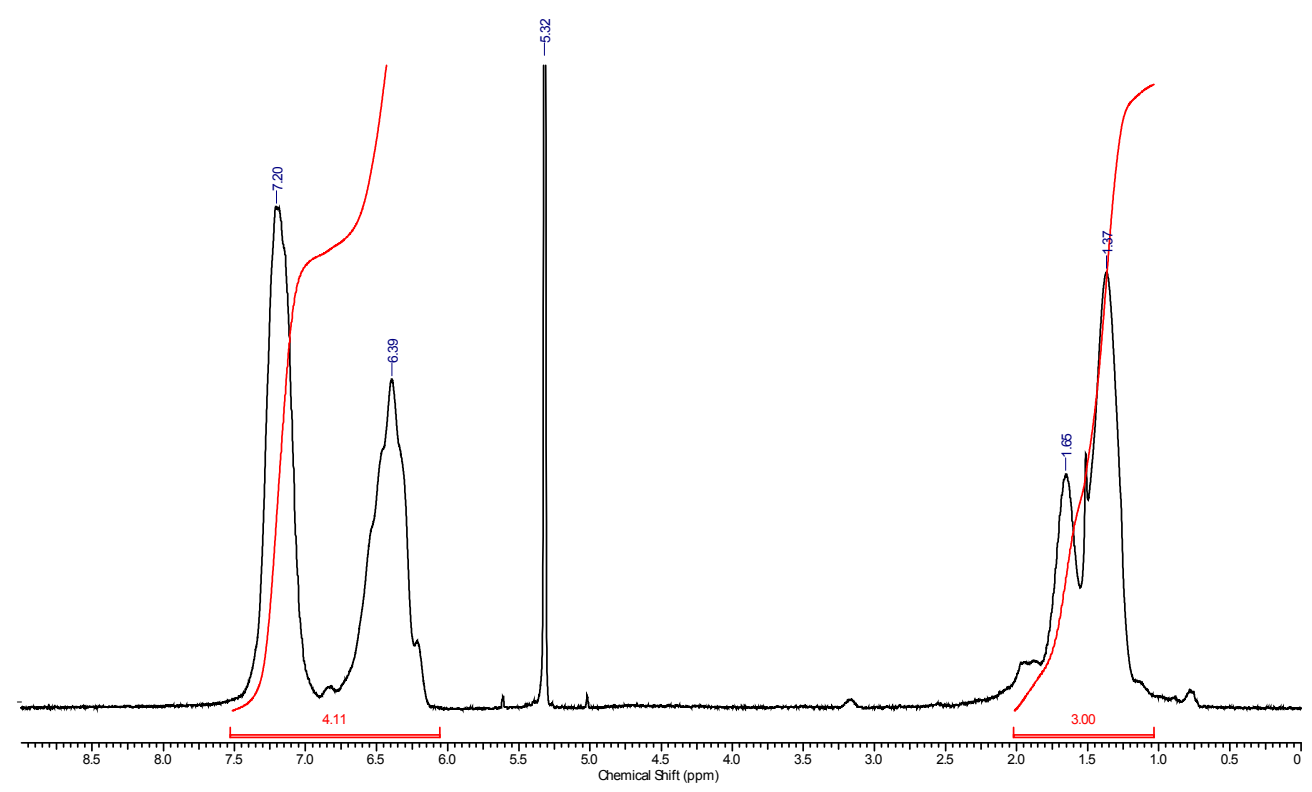

Figure S1. ${ }^{1} \mathrm{H}-\mathrm{NMR}$ spectrum of PSBr-S in dichloromethane- $\mathrm{d}_{2}$ (89\% bromination).

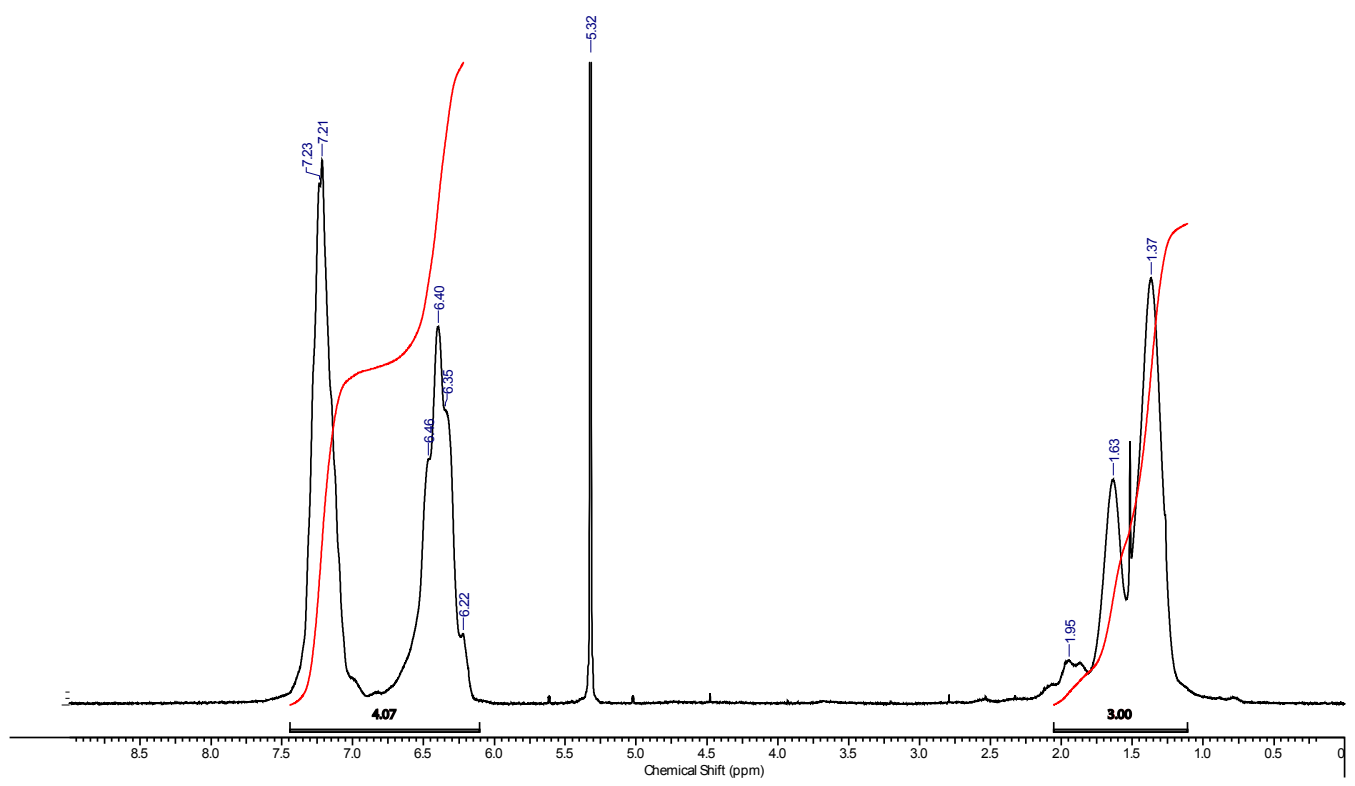

Figure S2. ${ }^{1} \mathrm{H}-\mathrm{NMR}$ spectrum of PSBr-L in dichloromethane- $\mathrm{d}_{2}$ (93\% bromination).

In both above spectra the aliphatic proton signals were set to a total integral of 3.0. The total aromatic signals are expected to have a value of 5.0 for the non-brominated polystyrene. The fully monobrominated polystyrene is expected to show an aromatic signal integral of 4.0. The ratio of brominated polystyrene in a mixture of both, brominated and non-brominated polystyrene can be calculated using:

$X=5$ - (observed total aromatic integral)

with $\mathrm{X}=$ ratio of brominated polystyrene

An average of $90 \%$ bromination was used for all further calculations for both samples. 


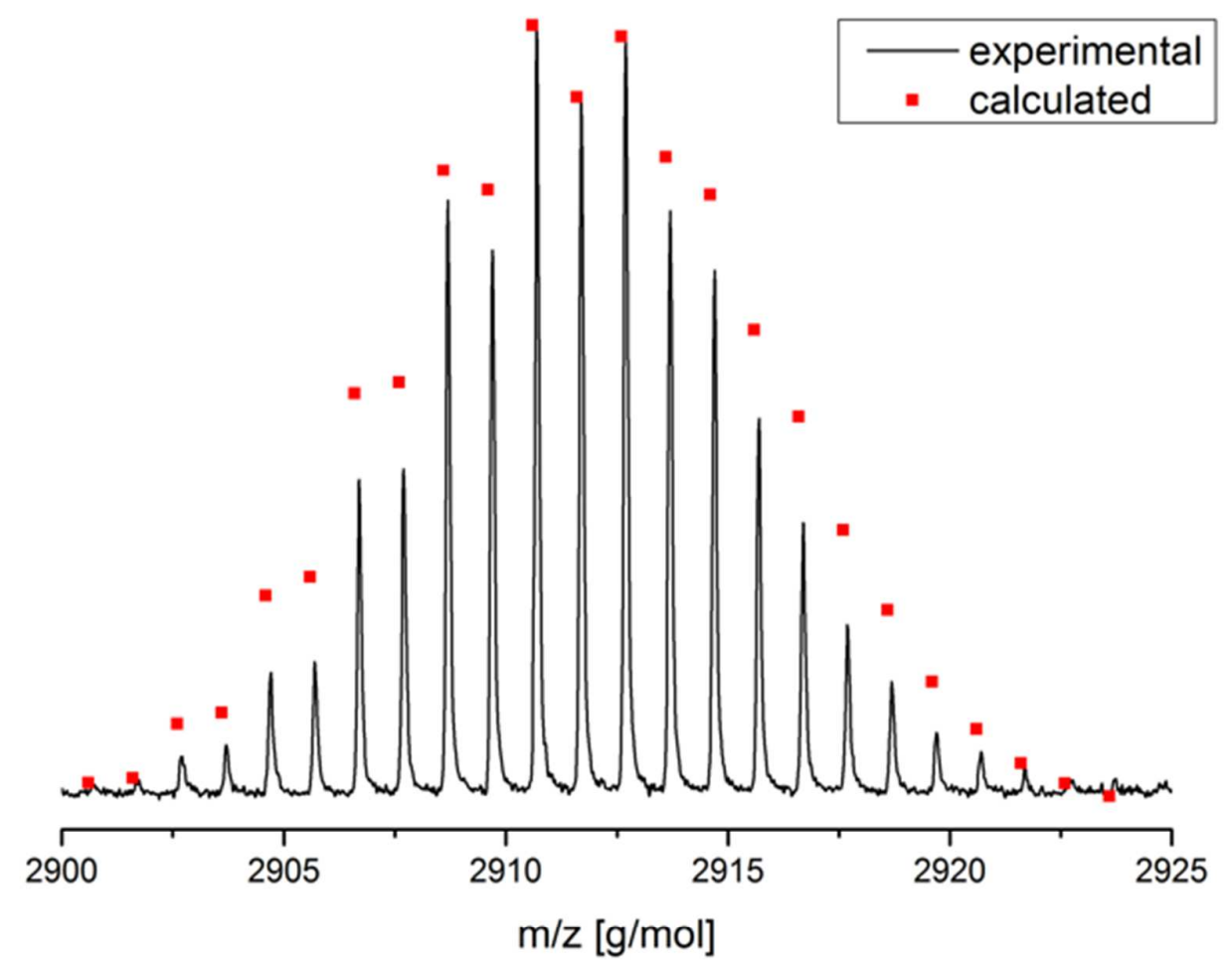

Figure S3. MALDI-TOF spectrum of brominated PS $\left(M_{n}=2 ' 000 \mathrm{~g} / \mathrm{mol}\right)$. Red dots correspond to the calculated theoretical isotope pattern.

5-(triisopropylsilyl)pent-4-yn-1-ol (1):<smiles>CC#CCCCO</smiles>

Synthesized according to literature ${ }^{3}$.

${ }^{1} \mathrm{H}$ NMR (300 MHz, CDCl$)$, [ppm]: $3.80\left(\mathrm{t},{ }^{3} \mathrm{~J}=6.10 \mathrm{~Hz}, 2 \mathrm{H}\right) ; 2.39\left(\mathrm{t},{ }^{3} \mathrm{~J}=6.84 \mathrm{~Hz}, 2 \mathrm{H}\right) ; 1.84-1.75$ (quint, $\left.{ }^{3} \mathrm{~J}=6.51 \mathrm{~Hz}, 2 \mathrm{H}\right) ; 1.09-1.04(\mathrm{~m}, 21 \mathrm{H})$.

5-(triisopropylsilyl)pent-4-yn-1-yl 4-methylbenzenesulfonate (2):<smiles>OCCCC#C[In-][AsH2]</smiles>

Synthesized with an adapted procedure from literature ${ }^{4}$ Yield: $76 \%$ over two steps

${ }^{1} \mathrm{H}$ NMR (300 MHz, $\left.\mathrm{CDCl}_{3}\right)$, [ppm]: 7.81-7.78 (d, $\left.{ }^{3} \mathrm{~J}=8.34 \mathrm{~Hz}, 2 \mathrm{H}\right) ; 7.36-7.33\left(\mathrm{~d},{ }^{3} \mathrm{~J}=8.07 \mathrm{~Hz}, 2 \mathrm{H}\right) ; 4.16$ $\left(\mathrm{t},{ }^{3} \mathrm{~J}=6.29 \mathrm{~Hz}, 2 \mathrm{H}\right) ; 2.45(\mathrm{~s}, 3 \mathrm{H}) ; 2.33\left(\mathrm{t},{ }^{3} \mathrm{~J}=6.84 \mathrm{~Hz}, 2 \mathrm{H}\right.$ ); $1.92-1.84$ (quint, ${ }^{3} \mathrm{~J}=6.51 \mathrm{~Hz}, 2 \mathrm{H}$ ); $1.04-0.99$ $(\mathrm{m}, 21 \mathrm{H})$.

${ }^{13} \mathrm{C}$ NMR $\left(75 \mathrm{MHz}, \mathrm{CDCl}_{3}\right)$, [ppm]: 144.68; 133.06; 129.83; 127.85; 106.37; 81.60; 69.02; 28.28; 21.61; $18.54 ; 17.68 ; 11.15$. 
$\underline{N-(5-(t r i i s o p r o p y l s i l y l) p e n t-4-y n-1-y l) c a r b i c ~ i m i d e ~(3): ~}$

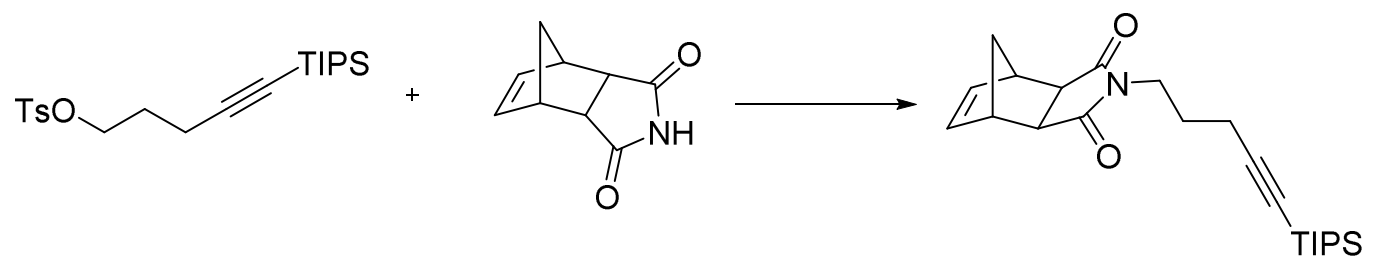

Synthesized with an adapted procedure from literature ${ }^{1}$.

Yield: $86 \%$

${ }^{1} \mathrm{H}$ NMR $\left(300 \mathrm{MHz}, \mathrm{CDCl}_{3}\right)$, [ppm]: $6.28\left(\mathrm{t},{ }^{3} \mathrm{~J}=1.74 \mathrm{~Hz}, 2 \mathrm{H}\right) ; 3.60-3.55(\mathrm{~m}, 2 \mathrm{H}) ; 3.28\left(\mathrm{t},{ }^{3} \mathrm{~J}=1.56 \mathrm{~Hz}, 2 \mathrm{H}\right)$; 2.68-2.67 (d, $\left.{ }^{3} \mathrm{~J}=1.10 \mathrm{~Hz}, 2 \mathrm{H}\right) ; 2.28\left(\mathrm{t},{ }^{3} \mathrm{~J}=7.24 \mathrm{~Hz}, 2 \mathrm{H}\right.$ ); $1.84-1.75$ (quint, ${ }^{3} \mathrm{~J}=7.93 \mathrm{~Hz}, 2 \mathrm{H}$ ); $1.54-1.50$ $\left(\mathrm{dt},{ }^{3} \mathrm{~J}=9.90 \mathrm{~Hz}, 1.43 \mathrm{~Hz}, 1 \mathrm{H}\right) ; 1.23-1.20\left(\mathrm{~d},{ }^{3} \mathrm{~J}=10.00 \mathrm{~Hz}, 1 \mathrm{H}\right) ; 1.08-1.04(\mathrm{~m}, 21 \mathrm{H})$.

${ }^{13} \mathrm{C}$ NMR (75 MHz, $\mathrm{CDCl}_{3}$ ), [ppm]: 177.84; 137.80; 106.88; 81.29; 47.79; 45.14; 42.75; 37.91; 27.08; $18.58 ; 17.79 ; 11.22$.

ESI-MS: 408.2, 409.2, 410.2, $411.2 \mathrm{~m} / \mathrm{z}(385.2$ + sodium).

Bis(2-(2-(2-methoxyethoxy)ethoxy)ethyl) exo-5-norbornene-2,3-dicarboyxylate(4):<smiles>CCOCCOCCOCCOCCOC(=O)C1C2C=CC(C2)C1C(=O)OCCOCCOCCOCC</smiles>

Synthesized with an adapted procedure from literature ${ }^{5}$.

Yield: $75 \%$

${ }^{1} \mathrm{H}$ NMR $\left(300 \mathrm{MHz}, \mathrm{CDCl}_{3}\right),[\mathrm{ppm}]: 6.01\left(\mathrm{t},{ }^{3} \mathrm{~J}=1.74 \mathrm{~Hz}, 2 \mathrm{H}\right) ; 4.09-4.04\left(\mathrm{dt},{ }^{3} \mathrm{~J}=12.21 \mathrm{~Hz},{ }^{3} \mathrm{~J}=5.23 \mathrm{~Hz}\right.$, $2 \mathrm{H}) ; 3.92-3.86\left(\mathrm{dt},{ }^{3} \mathrm{~J}=11.77 \mathrm{~Hz},{ }^{3} \mathrm{~J}=4.80 \mathrm{~Hz}, 2 \mathrm{H}\right) ; 3.48-3.43(\mathrm{~m}, 16 \mathrm{H}) ; 3.35-3.33(\mathrm{~m}, 4 \mathrm{H}) ; 3.17(\mathrm{~s}, 6 \mathrm{H})$; $2.88\left(\mathrm{t},{ }^{3} \mathrm{~J}=1.74 \mathrm{~Hz}, 2 \mathrm{H}\right) ; 2.44\left(\mathrm{~d},{ }^{3} \mathrm{~J}=1.74 \mathrm{~Hz}, 2 \mathrm{H}\right) ; 1.87-1.85\left(\mathrm{~d},{ }^{3} \mathrm{~J}=9.16 \mathrm{~Hz}, 1 \mathrm{H}\right) ; 1.28-1.25\left(\mathrm{dt},{ }^{2} \mathrm{~J}=9.16\right.$ $\left.\mathrm{Hz},{ }^{3} \mathrm{~J}=1.74 \mathrm{~Hz}, 1 \mathrm{H}\right)$.

ESI-MS: 497.2, 498.2, 499.2, $500.2 \mathrm{~m} / \mathrm{z}(474.2+$ sodium $)$.

Ring-Opening Metathesis Polymerization (poly(1)):

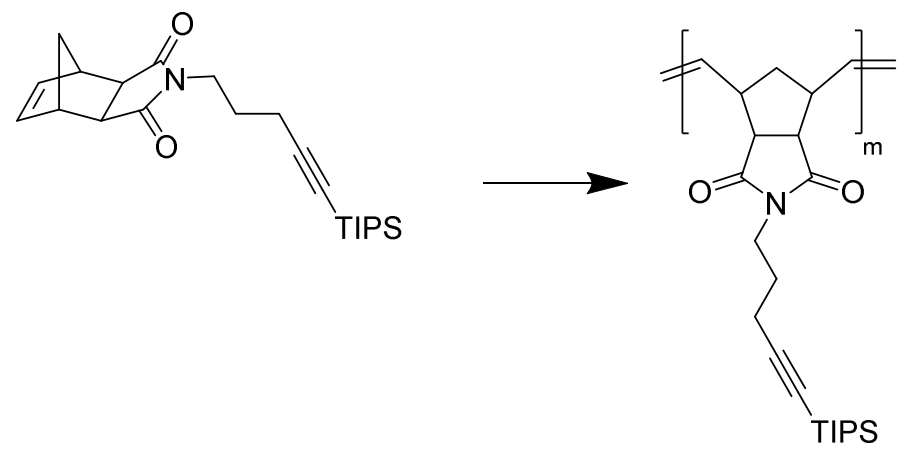

Compound $3(1.0 \mathrm{~g}, 2.59 \mathrm{mmol})$ was dissolved in degassed dichloromethane $(4 \mathrm{~mL})$ and a solution of Grubbs ' first-generation catalyst $(5.5 \mathrm{mg}$ for polymer of $150 \mathrm{kDa})$ in degassed dichloromethane $(1 \mathrm{~mL})$ was added in one shot. After stirring for 9 hours at room temperature, the polymerization was terminated with ethyl vinyl ether $(0.2 \mathrm{~mL})$. The polymer was precipitated into a 10 -fold excess of icecold methanol, filtered off and dried under vacuo. Yield: $978 \mathrm{mg}, 98 \%$. 


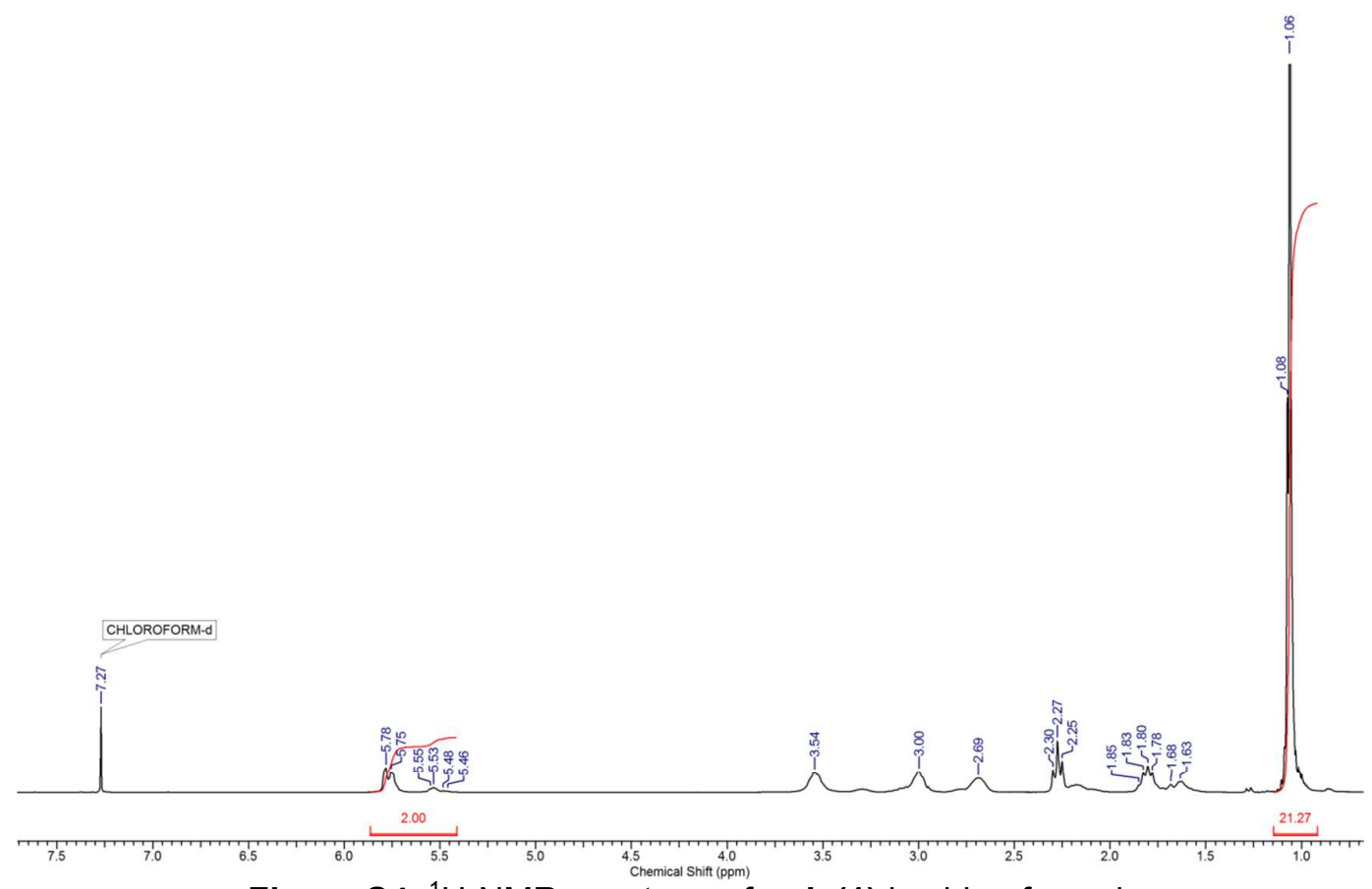

Figure S4. ${ }^{1} \mathrm{H}-\mathrm{NMR}$ spectrum of poly(1) in chloroform-d.

\section{Ring-Opening Metathesis Polymerization (poly(1-stat-2)-L):}

A mixture of compounds 3 ( $379 \mathrm{mg}, 0.98 \mathrm{mmol})$ and $4(200 \mathrm{mg}, 0.42 \mathrm{mmol})$ was dissolved in degassed dichloromethane $(5 \mathrm{~mL})$. A solution of Grubbs` first-generation catalyst (5.0 mg for polymer of $100 \mathrm{kDa}$ ) in degassed dichloromethane $(1 \mathrm{~mL})$ was added in one shot. After stirring for 7 hours at room temperature, the polymerization was terminated with ethyl vinyl ether $(0.2 \mathrm{~mL})$. The polymer was precipitated into a 10-fold excess of ice-cold methanol, filtered off and dried under vacuo. Yield: $560 \mathrm{mg}, 97 \%$

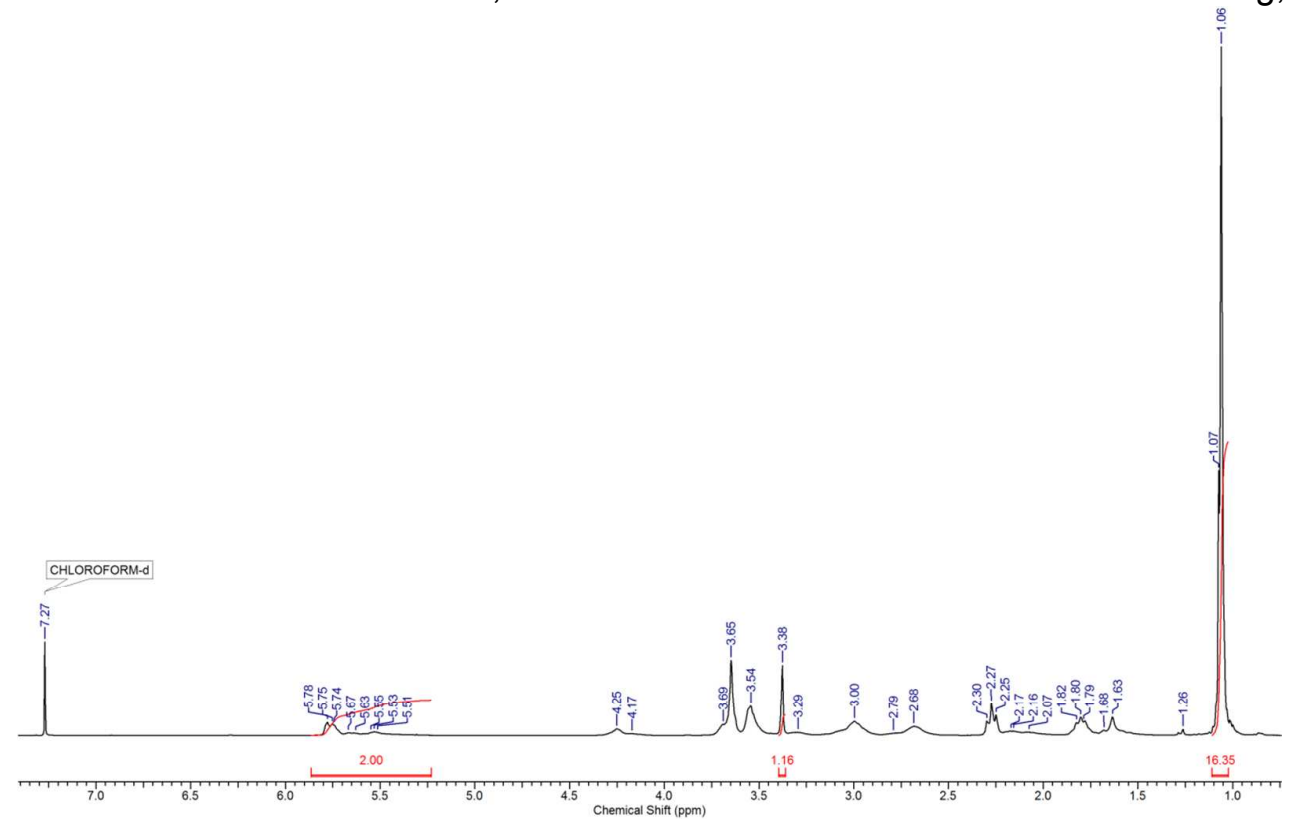

Figure S5. ${ }^{1} \mathrm{H}-\mathrm{NMR}$ spectrum of poly(1-stat-2)-L in chloroform-d. 


\section{Alkyne-deprotection (poly(D1-stat-2)-L):}

Polymer poly(1-stat-2)-L (200 mg) was dissolved in THF/ $\mathrm{H}_{2} \mathrm{O}(5 \%, 5 \mathrm{~mL})$ and TBAF in THF $(1 \mathrm{M}, 1.0$ $\mathrm{mL}$ ) was added. After stirring overnight at room temperature, the polymer was purified via dialysis in ethanol. Yield: $92 \mathrm{mg}, 63 \%$.

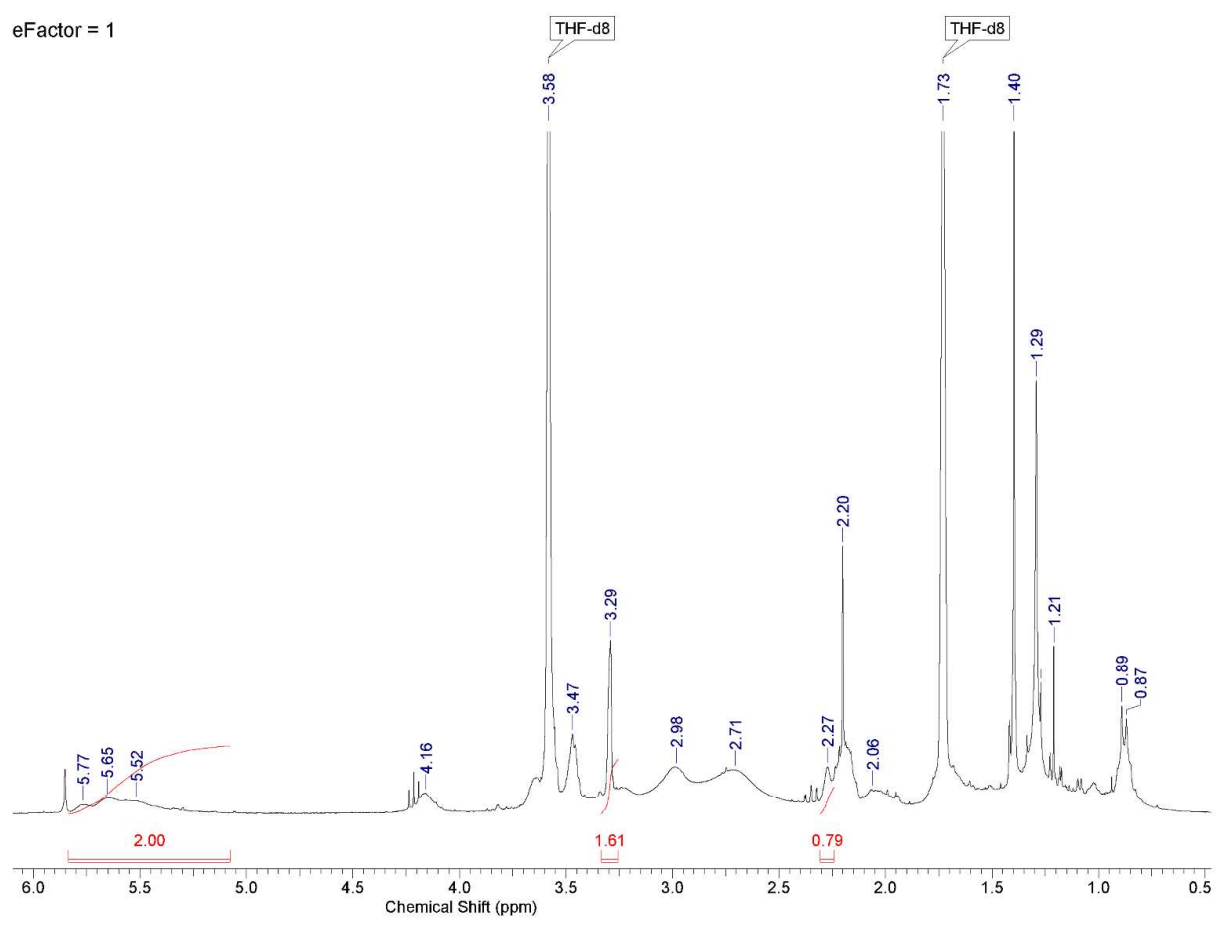

Figure S6. ${ }^{1} \mathrm{H}-\mathrm{NMR}$ spectrum of poly(D1-stat-2)-L in THF-d8.

\section{Ring-Opening Metathesis Polymerization (poly(1-stat-2)-S):}

\section{Same procedure as poly(1-stat-2)-L.}

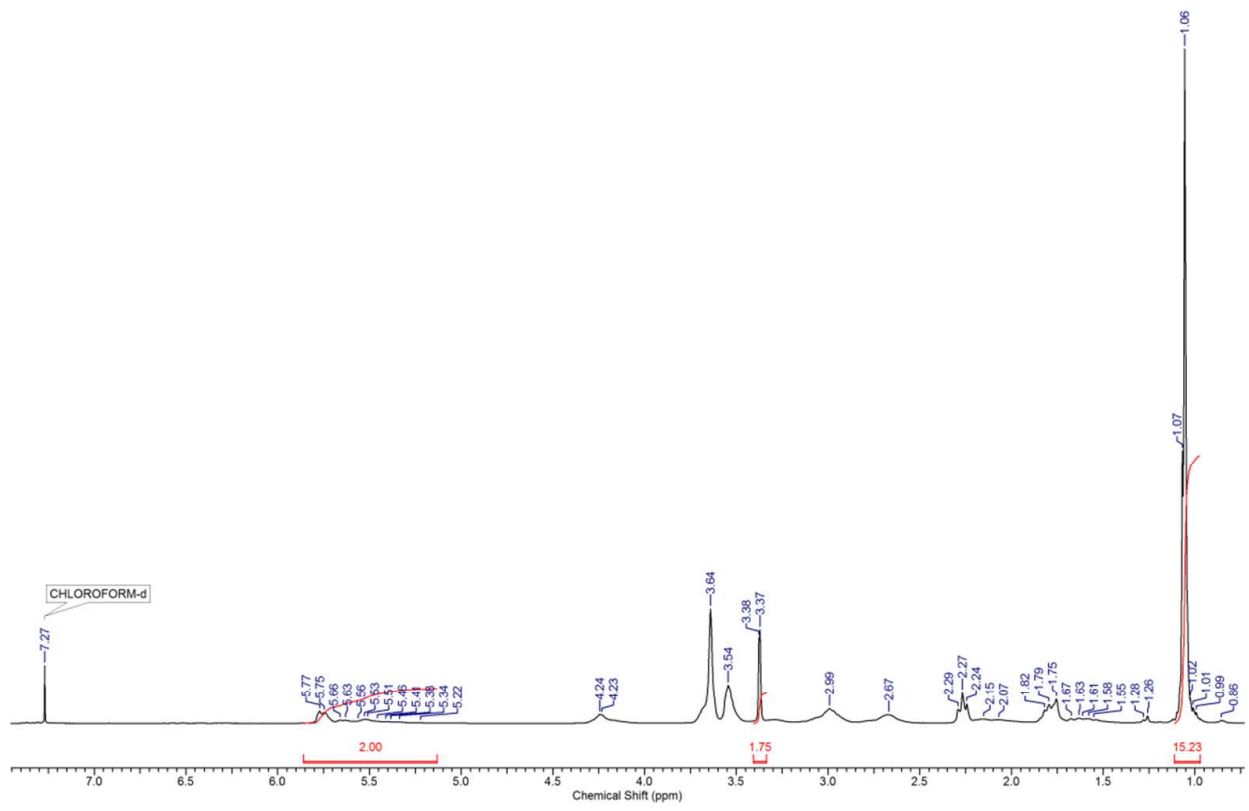

Figure S7. ${ }^{1} \mathrm{H}-\mathrm{NMR}$ spectrum of poly(1-stat-2)-S in chloroform-d. 
Alkyne-deprotection (poly(D1-stat-2)-S):

Same procedure as poly(D1-stat-2)-L.

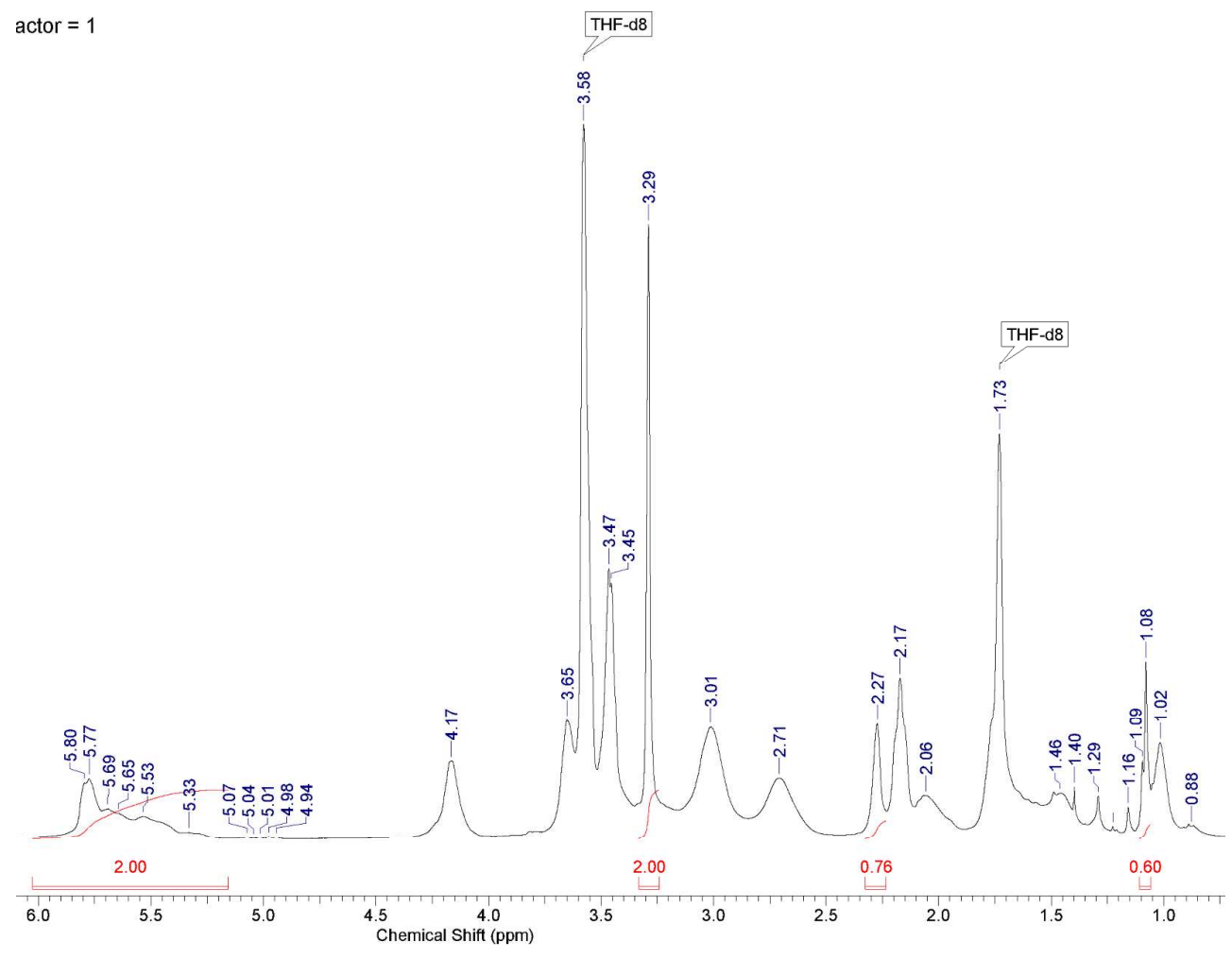

Figure S8. ${ }^{1} \mathrm{H}-\mathrm{NMR}$ spectrum of poly(D1-stat-2)-S in THF-d8.

\section{Sonication experiment:}

Sonication experiments were performed under $\mathrm{N}_{2}$ in Super Purity ROMIL-SpS THF using custom made Suslick cells. ${ }^{6}$ Solutions were purged with $\mathrm{N}_{2} 30$ minutes prior to sonication. $20 \mathrm{ml}, 0.75 \mathrm{mg} / \mathrm{ml}$ solutions of corresponding polymers were cooled to $0{ }^{\circ} \mathrm{C}$ using refrigerated circulating bath then pulse sonicated ( $0.5 \mathrm{~s}$ on, $1.0 \mathrm{~s}$ off) at a power of $10.4 \mathrm{~W} / \mathrm{cm}^{2} .500 \mu \mathrm{l}$ aliquots were withdrawn from the cell and analyzed directly by SEC. 


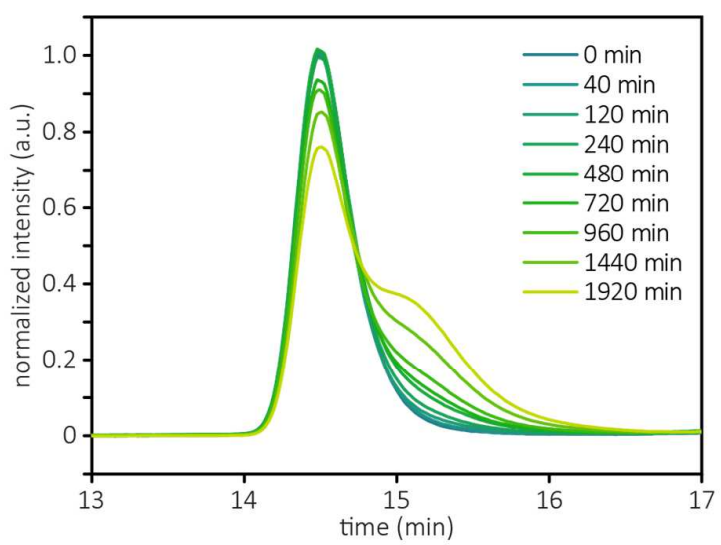

Figure S9. Size exclusion chromatograms showing chain scission events for $P S\left(M_{n}=25^{\circ} 000 \mathrm{~g} / \mathrm{mol}\right)$ upon sonication with sonication parameters applied in this study.

Model
\begin{tabular}{|l|r|r|r|}
\hline Equation & ExpDec1 & \\
\hline Reduced Chi-Sqr & $7.70 \mathrm{E}-05$ & & \\
\hline Adj. R-Square & 0.99937 & & \\
\hline & & Value & Standard Error \\
\hline PS-L & y0 $/ \mathrm{t} 1)+\mathrm{y} 0$ & & \\
\hline PS-L & A1 & -0.04062 & 0.01688 \\
\hline PS-L & t1 & 1.04868 & 0.01569 \\
\hline PS-L & $\mathrm{k}$ & 868.0331 & 31.60305 \\
\hline PS-L & tau & 0.00115 & $4.19 \mathrm{E}-05$ \\
\hline
\end{tabular}

\begin{tabular}{|l|r|r|r|}
\hline Model & \multicolumn{4}{|l|}{ ExpDec1 } \\
\hline Equation & $\mathrm{y}=\mathrm{A} 1 * \exp (-\mathrm{x} / \mathrm{t} 1)+\mathrm{y} 0$ & & \\
\hline Reduced Chi-Sqr & $3.32 \mathrm{E}-05$ & & \\
\hline Adj. R-Square & 0.99973 & & \\
\hline & & Value & Standard Error \\
\hline & & 0.02485 & 0.00817 \\
\hline PSBr-L & y0 & 0.98052 & 0.00779 \\
\hline PSBr-L & A1 & 701.75176 & 14.95044 \\
\hline PSBr-L & t1 & 0.00143 & $3.04 \mathrm{E}-05$ \\
\hline PSBr-L & k & 486.41725 & 10.36286 \\
\hline PSBr-L & tau & &
\end{tabular}

Figure S10. Exponential decay fit of the $\mathrm{P}_{\max }$ as a function of time (Figure 3a) for PS-L (cyan) and PSBr-L (red). Degradation rates were fitted to 1.43 and $1.15 \times 10^{-3} \mathrm{~min}^{-1}$ respectively.

a)

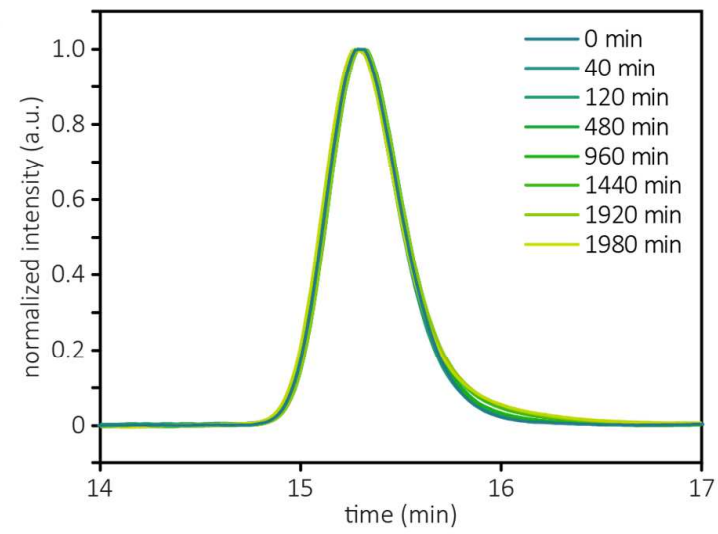

b)

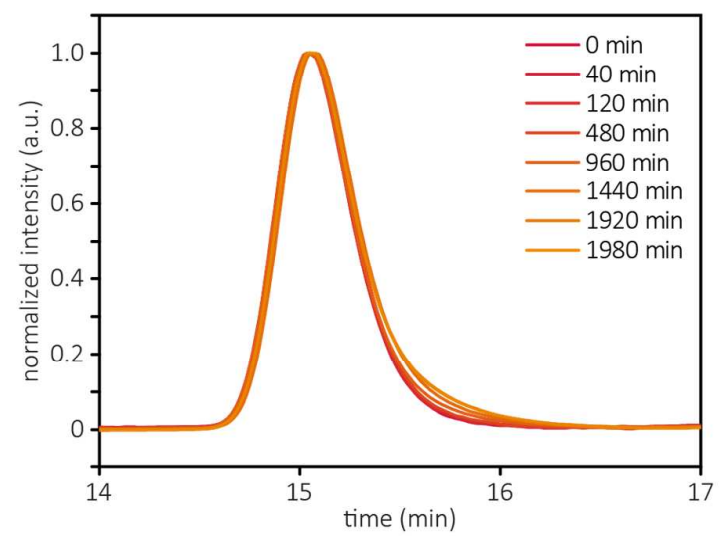

Figure S11. Size exclusion chromatograms showing no change in molecular weight for a) PS-S and b) PSBr-S upon sonication. 


Model
\begin{tabular}{|l|r|r|r|}
\hline Equation & $\mathrm{y}=\mathrm{A} 1^{*} \exp (-\mathrm{x} / \mathrm{t} 1)+\mathrm{y} 0$ & & \\
\hline Reduced Chi-Sqr & 0.00376 & & \\
\hline Adj. R-Square & 0.97446 & & \\
\hline & & Value & Standard Error \\
\hline E & $\mathrm{y} 0$ & 0.79791 & 0.04742 \\
\hline $\mathrm{E}$ & $\mathrm{A} 1$ & 0.97369 & 0.0645 \\
\hline $\mathrm{E}$ & $\mathrm{t} 1$ & 133.3008 & 26.71971 \\
\hline $\mathrm{E}$ & $\mathrm{k}$ & 0.0075 & 0.0015 \\
\hline $\mathrm{E}$ & $\mathrm{tau}$ & 92.39708 & 18.52069 \\
\hline
\end{tabular}

\begin{tabular}{|l|r|r|r|}
\hline Model & \multicolumn{1}{|l|}{ ExpDec1 } \\
\hline Equation & $\mathrm{y}=\mathrm{A} 1^{*} \exp (-\mathrm{x} / \mathrm{t} 1)+\mathrm{y} 0$ & & \\
\hline Reduced Chi-Sqr & 0.00124 & & \\
\hline Adj. R-Square & 0.9917 & & \\
\hline & & Value & Standard Error \\
\hline D & y0 & 0.80979 & 0.02362 \\
\hline D & A1 & 0.98281 & 0.03666 \\
\hline D & t1 & 113.86602 & 12.23521 \\
\hline D & k & 0.00878 & $9.44 \mathrm{E}-04$ \\
\hline D & tau & 78.92591 & 8.4808 \\
\hline
\end{tabular}

Figure S12. Exponential decay fit of the graph $M_{n} /\left(M_{0}-M_{\text {lim }}\right)$ as a function of time (Figure $\left.5 c\right)$ for poly(D1-stat-2)-L (cyan) and poly(1-stat-2)-L (red). It is assumed that the chain scission follows first order kinetics $\left(\frac{d M_{n}}{d t}=k\left(M_{n}-M_{\text {lim }}\right)\right)$. Degradation rates were fitted to $8.810^{-4} \mathrm{~min}^{-1}$ and $7.510^{-4} \mathrm{~min}^{-1}$ respectively.

a)

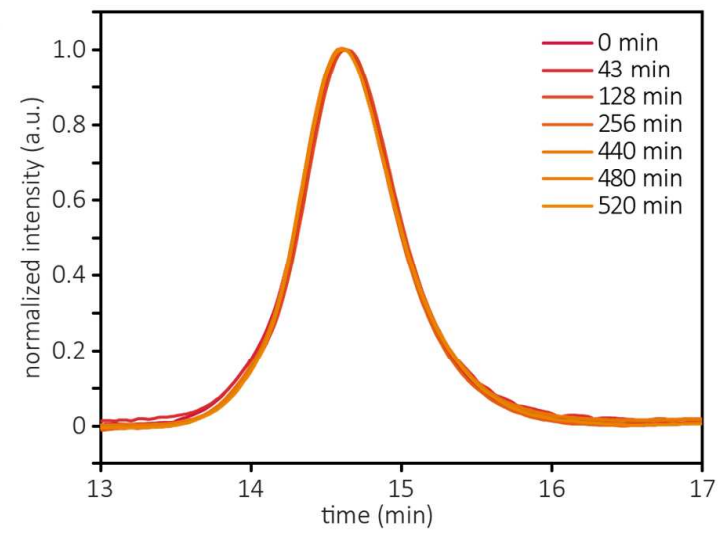

b)

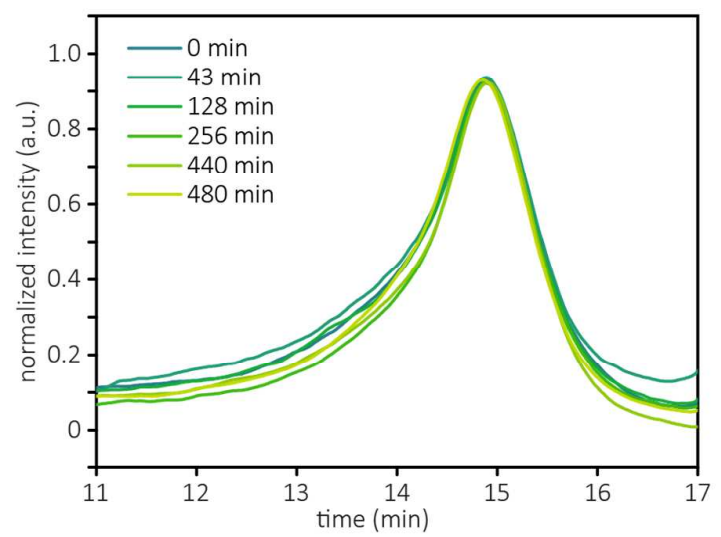

Figure S13. Size exclusion chromatograms showing no change in molecular weight for a) poly(1-stat2)-S and b) poly(D1-stat-2)-S upon sonication.

Mathematical model

A detailed kinetic model of the polymer degradation was built by writing the mass balance of the concentration of chains $N_{n}$ with $n$ repeating units (hereafter referred to as chains with length $n$ ).

If such chains are the ones that cannot be generated by scission of any larger chains, than their mass balance only involves first order kinetics consumption due to ultrasonic-induced scission:

$\frac{d N_{n}}{d t}=-K_{n} \cdot N_{n}$

If instead a chain is not only broken but also generated by the scission of longer chains, then its mass balance reads:

$\frac{d N_{n}}{d t}=-K_{n} \cdot N_{n}+\sum_{i=m}^{l} K_{i} \cdot N_{i} \cdot \Gamma_{i, n}$ 
Where the indices $m$ and $/$ correspond respectively to the smallest and largest chains that can produce fragments of mass $n$, and $\Gamma_{i, n}$ is the fragment distribution function, i.e., the probability that the scission event of a chain with mass $i$ will producing a fragment with mass $n$ (which of course implies $n<i$ ). The mass balance of a chain that can only be produced as a result of the fragmentation, but which cannot be broken by the sonication process is given by:

$$
\frac{d N_{n}}{d t}=\sum_{i=m}^{l} K_{i} \cdot N_{i} \cdot \Gamma_{i, n}
$$

The kinetic constants are a function of the chain length. The following kinetics equation has been used:

$$
K_{i}=\kappa\left(i-c_{o f f}\right)^{\lambda}
$$

In Equation(0.0), $c_{\text {off }}$ is the cutoff length, below which no scission occurs. Different values of the exponent $\lambda$ have been proposed in the literature, but usually they all are close to one ${ }^{7}$, and in all our simulations $\lambda=1$ has been used. This means the chains longer than the cutoff can be broken at a rate that linearly increases with their length. The proportionality constant $\kappa$ is considered as a fitting parameter, which is difficult to quantify exactly, since it depends on the polymer concentration and on the set-up used to perform the scission experiments. The simulation results suggest that $\kappa$ is sample dependent. The values of $\kappa$ used in the calculations for the different samples are listed in table 1.

What is crucial for the solution of the system of linear differential equations is the functional form of the fragment distribution function. It is assumed that $\Gamma_{i, n}$ obeys the following constraint:

$$
\sum_{n=1}^{i-1} n \cdot \Gamma_{i, n}=i
$$

which expresses the conditions that the sum of the masses of all fragments equals the mass of the original chain.

The assumption for the scission process made in this work is the following: the fragment distribution function is assumed to be a Gaussian centered at the center of the center of the chain, and rapidly decaying:

$\Gamma_{i, n}=A e^{-\frac{\left(\frac{i}{2}-n\right)^{2}}{2\left(\sigma \frac{i}{2}\right)^{2}}}$

In equation (0.0), $\sigma$ is the parameter determining the variance of the Gaussian distribution, i.e., its broadness. In this work, $\sigma$ has been set equal to 0.2 . The normalization constant $A$ is directly determined from equation (0.0). Since the breakage process is discrete and not continuous, equation $(0.0)$ is kept in a discrete form. From Equation (0.0) one can determine the range of $n$ values that are effectively used. In fact, when the argument of the exponential equals -9 , the value of the exponential is about $1.23 e-4$, i.e., negligible. Therefore, we obtain:

$$
\begin{aligned}
& \left(\frac{i}{2}-n\right)^{2}=18\left(\sigma \frac{i}{2}\right)^{2} \Rightarrow \frac{i}{2}(1-\sqrt{18} \sigma) \leq n \leq \frac{i}{2}(1+\sqrt{18} \sigma) \\
& \text { if }(1-\sqrt{18} \sigma)>0 \text { and }(1+\sqrt{18} \sigma) \leq 2
\end{aligned}
$$


Equation (0.0) provides the range of admissible $n$ values.

The solution of the system of linear differential equations can be easily performed analytically using matrix exponentials. Using a vector notation, the system of equations reads:

$$
\frac{d \mathbf{N}}{d t}=\mathbf{A} \cdot \mathbf{N}
$$

The solution, subject to the initial condition $\mathbf{N}(0)=\mathbf{N}_{0}$, is given by:

$$
\mathbf{N}(t)=e^{\mathbf{A} t} \cdot \mathbf{N}_{0}
$$

The solution of the system of equations (0.0) has been computed using Matlab ${ }^{\odot}$. The initial condition was obtained from the measured initial molecular weight distribution of the polymers, converted into a number molecular weight distribution.

From the full model, it is possible to derive an equation for the time evolution of the number average molecular weight.

$$
\frac{d M_{n}}{d t}=\frac{d}{d t}\left(\frac{\sum_{i} N_{i} M_{i}}{\sum_{i} N_{i}}\right)=\frac{\sum_{i} \frac{d N_{i}}{d t} M_{i}}{\sum_{i} N_{i}}-\frac{\sum_{i} N_{i} M_{i}}{\left(\sum_{i} N_{i}\right)^{2}} \sum_{i} \frac{d N_{i}}{d t}
$$

This can be rearranged as:

$$
\frac{d M_{n}}{d t}=\frac{\sum_{i}\left(-K_{i} \cdot N_{i}+\sum_{j} K_{j} \cdot N_{j} \cdot \Gamma_{j, i}\right) M_{i}}{\sum_{i} N_{i}}-\frac{\sum_{i} N_{i} M_{i}}{\left(\sum_{i} N_{i}\right)^{2}} \sum_{i}\left(-K_{i} \cdot N_{i}+\sum_{j} K_{j} \cdot N_{j} \cdot \Gamma_{j, i}\right)
$$

Finally, after some algebraic manipulations, we arrive to the final expression:

$$
\frac{d M_{n}}{d t}=-\frac{M_{n}}{\left(\sum_{i} N_{i}\right)} \sum_{i}\left(-K_{i} \cdot N_{i}+\sum_{j} K_{j} \cdot N_{j} \cdot \Gamma_{j, i}\right)=-K_{n} M_{n}
$$

A plot of the kinetic constant $K_{n}$ in the case of the protected polymer as function of the molecular weight is linear with the molecular weight, with a cutoff a bit lower than the one used in Equation (0.0). This shows that the number average molecular weight follows the equation:

$$
\frac{d M_{n}}{d t}=-\kappa\left(M_{n}-C\right) M_{n}
$$

The solution of equation $(0.0)$ is the following:

$$
M_{n}=\frac{C}{1-\left(\frac{M_{n}^{0}-C}{M_{n}^{0}}\right) \exp (-\kappa \cdot C \cdot t)}
$$


Equation (0.0) can fit the $M_{n}$ data as a function of time very well, as figure S12a clearly indicates.

One should note the simulation of PSBr-L data is somehow difficult. The model developed is based on recovering the initial molecular weight distribution of the polymer from the chromatograms. However, the chromatograms of PS-L and PSBr-L are almost identical, suggesting that their hydrodynamic radius is virtually identical. Recovering the molecular weight distribution is therefore impossible from the chromatograms. However, the time evolution of the molecular weight distribution is also almost identical in the two cases. This shows that the model would do an identically good job in predicting the time evolution of PSBr-L, given that the chains have the same number of monomer units.

\section{a)}

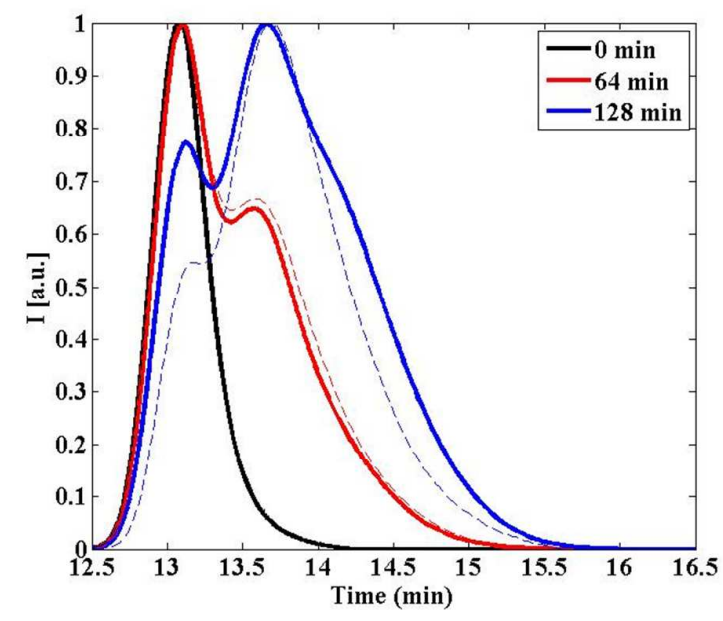

b)

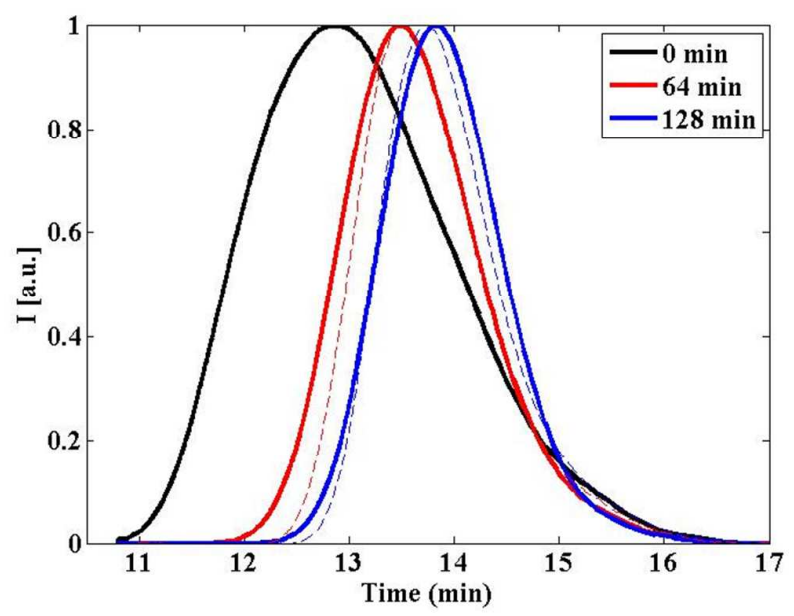

Figure S14. Size exclusion chromatograms of PS with a) narrow and b) broad molar-mass dispersity upon sonication. The dashed lines are experimental data, while the solid lines are model predictions. 


\section{a)}

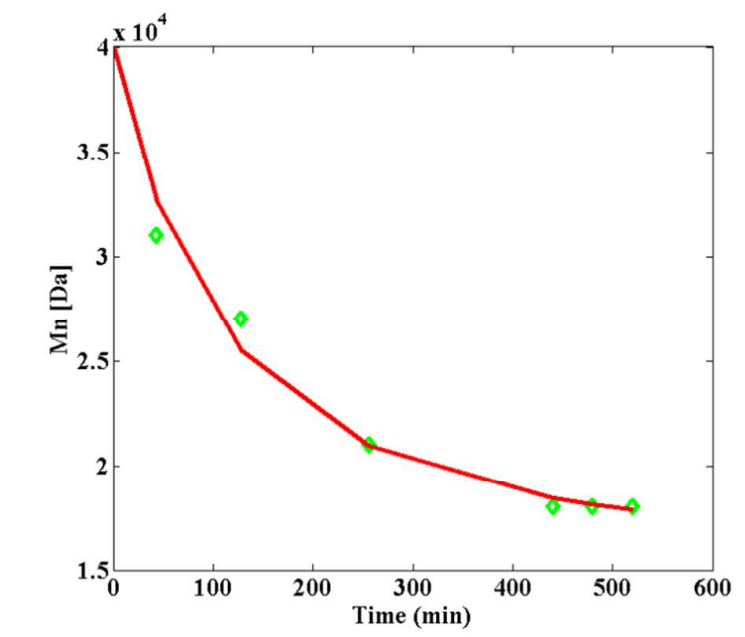

b)

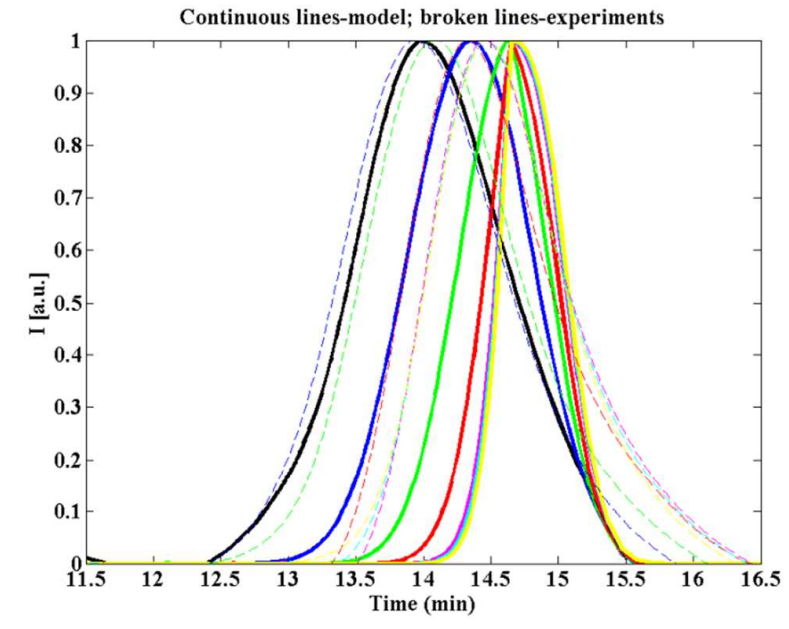

Figure S15. a) Time evolution of $M_{n}$ of poly(D1-stat-2)-L. The line is the model prediction with Equation (0.14) b) Time evolution of the size exclusion chromatograms for poly(D1-stat-2)-L, compared to model predictions.

Table S1. Values of $\kappa$ used in the simulations (in $\mathrm{s}^{-1}$ )

\begin{tabular}{|c|c|c|c|c|c|}
\hline $\begin{array}{c}\text { poly(1-stat-2)- } \\
\text { L }\end{array}$ & $\begin{array}{c}\text { poly(D1-stat- } \\
\text { 2)-L }\end{array}$ & PS narrow & PS broad & PS-L & PSBr-L \\
\hline 0.125 & 0.1 & 0.0125 & 0.2857 & 0.0125 & 0.0125 \\
\hline
\end{tabular}

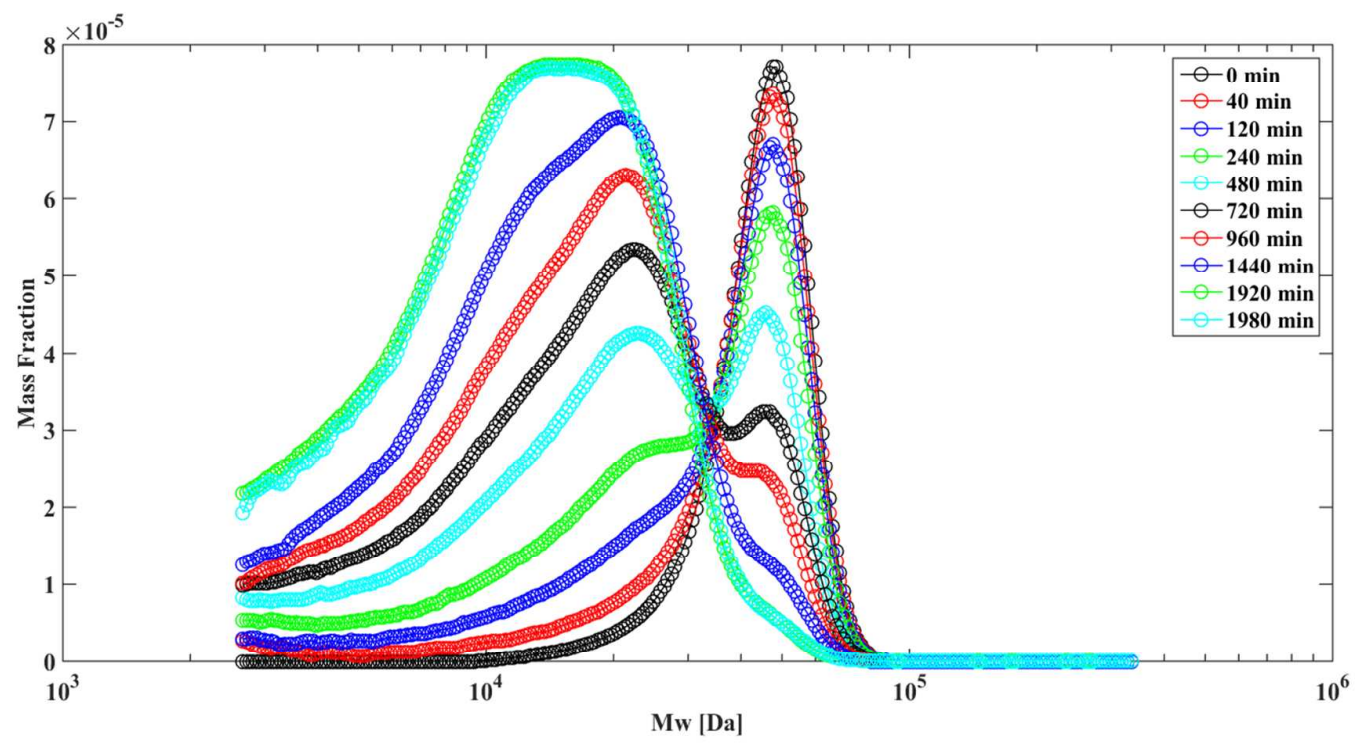

Figure S16. Size exclusion chromatograms (SECS) showing the bimodal mass distribution appearance for PS-L upon sonication of a solution of this polymer in THF for the times indicated in the graphs. This graph corresponds to data in Figure 2a but was instead plotted as the mass fraction as a function of the molecular weight. 


\section{References:}

(1) Schaefer, M.; Hanik, N.; Kilbinger, A. F. M. Macromolecules 2012, 45, 6807.

(2) Busch, M.; Weber, W.; Zink, H. Journal für Praktische Chemie 1940, 155, 163.

(3) Layton, M. E.; Morales, C. A.; Shair, M. D. J. Am. Chem. Soc. 2002, 124, 773.

(4) Davison, E. C.; Forbes, I. T.; Holmes, A. B.; Warner, J. A. Tetrahedron 1996, 52, 11601.

(5) Bauer, T.; Slugovc, C. Journal of Polymer Science Part A: Polymer Chemistry 2010, 48, 2098.

(6) Berkowski, K. L.; Potisek, S. L.; Hickenboth, C. R.; Moore, J. S. Macromolecules 2005, 38, 8975.

(7) Sivalingam, G.; Agarwal, N.; Madras, G. AlChE J. 2004, 50, 2258. 